Journal of Low Temperature Physics manuscript No.

(will be inserted by the editor)

E. M. George ${ }^{1}$ - J. E. Austermann ${ }^{3}$ - J. A.

Beall $^{4}$. D. Becker ${ }^{4}$. B. A. Benson 2,13 . L.

E. Bleem ${ }^{2,12}$. J. E. Carlstrom ${ }^{2,5,12,13,14}$

C. L. Chang $2,5,13$. H- M. Cho ${ }^{4}$. A. T.

Crites $^{2,14}$. M. A. Dobbs ${ }^{6}$. W. Everett $^{3}$

N. W. Halverson ${ }^{3,11}$. J. W. Henning ${ }^{3}$.

G. C. Hilton ${ }^{4}$. W. L. Holzapfel ${ }^{1}$. J.

Hubmayr $^{4}$. K. D. Irwin ${ }^{4}$. D. $\mathrm{Li}^{4}$. M.

Lueker $^{8} \cdot$ J. J. McMahon ${ }^{9} \cdot$ J. Mehl $^{2,13}$.

J. Montgomery ${ }^{2,12} \cdot$ T. Natoli ${ }^{2,12} \cdot \mathbf{J}$.

P. Nibarger ${ }^{4}$. M. D. Niemack ${ }^{4}$. V.

Novosad $^{7}$ · J. E. Ruhl ${ }^{10}$ - J. T. Sayre ${ }^{10}$. E.

Shirokoff $^{8}$. K. T. Story ${ }^{2,12}$. G. Wang ${ }^{5}$. V.

Yefremenko $^{5,7} \cdot$ K. W. Yoon ${ }^{4} \cdot$ E. Young ${ }^{1}$

\title{
A Study of Al-Mn Transition Edge Sensor Engineering for Stability
}

November 12, 2013

\footnotetext{
Abstract The stability of Al-Mn transition edge sensor (TES) bolometers is studied as we vary the engineered TES transition, heat capacity, and/or coupling between the heat capacity and TES. We present thermal structure measurements of

E-mail: lizinvt@berkeley.edu (E. M. George)

${ }^{1}$ University of California, Berkeley, 151 LeConte Hall Berkeley, CA 94720, USA

${ }^{2}$ Kavli Institute for Cosmological Physics, Department of Physics, Enrico Fermi Institute, The University of Chicago, Chicago, IL 60637, USA

${ }^{3}$ Department of Astrophysical and Planetary Sciences, University of Colorado, Boulder, Colorado, 80309, USA

${ }^{4}$ NIST, Boulder, CO 80305, USA

${ }^{5}$ High Energy Physics Division, Argonne National Laboratory, Argonne, IL 60439, USA

${ }^{6}$ McGill University, Montreal, Quebec, Canada

${ }^{7}$ Materials Science Division, Argonne National Laboratory, Argonne, IL 60439, USA

${ }^{8}$ California Institute of Technology, Pasadena, CA 91125, USA

${ }^{9}$ University of Michigan, Ann Arbor, Michigan, USA

${ }^{10}$ Case Western Reserve University, Cleveland, Ohio 44106, USA

${ }^{11}$ Department of Physics, University of Colorado, Boulder, CO 80309

12 Department of Physics, University of Chicago, 5640 South Ellis Avenue, Chicago, IL, USA 60637

${ }^{13}$ Enrico Fermi Institute, University of Chicago, 5640 South Ellis Avenue, Chicago, IL, USA 60637

${ }^{14}$ Department of Astronomy and Astrophysics, University of Chicago, 5640 South Ellis Avenue, Chicago, IL, USA 60637
} 
each of the 39 designs tested. The data is accurately fit by a two-body bolometer model, which allows us to extract the basic TES parameters that affect device stability. We conclude that parameters affecting device stability can be engineered for optimal device operation, and present the model parameters extracted for the different TES designs.

Keywords TES, frequency domain multiplexing, stability, bolometer, Al-Mn

\section{Introduction}

High-sensitivity measurements of the cosmic microwave background (CMB) polarization can constrain the sum of the neutrino masses and the energy scale of inflation, which informs the viability of inflationary models. To make these measurements, we developed 84-pixel arrays of $150 \mathrm{GHz} \mathrm{Al}-\mathrm{Mn}$ transition edge sensor (TES) polarimeters 1 for the South Pole Telescope polarimeter (SPTpol), which began observations in February 2012 2 . The detectors are read out with a digital frequency domain multiplexing (fMUX) system. $\frac{3}{-}$ Initial detector prototypes exhibited instability consistent with a compound TES model, described in Lueker et al. (2008) $\stackrel{8}{\underline{8}}$ when operated at moderate depths in the superconducting transi-

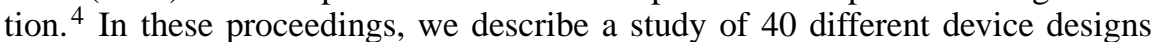
that were devised to address TES stability criteria.

\section{Stability Criteria for TESes}

Figure 1 is a model of a TES with an additional heat capacity, commonly known as a "Bandwidth Limiting Interface Normally of Gold" (BLING), coupled to the TES through a thermal link. The TES has a heat capacity $C_{T E S}=C_{0} / \eta$, resistance $R_{T E S}$, and is strongly coupled to the BLING by a thermal conductance $G_{\text {int }}=\gamma G_{0}$. The BLING has a heat capacity $C_{0}$, which is connected to the thermal bath by a conductance $G_{0}$. In our devices, the BLING is strongly coupled to the TES, $(\gamma \gg 1)$ and the heat capacity of the BLING is much greater than the heat capacity of the TES, $(\eta \gg 1)$. The TES is AC voltage biased in negative electrothermal feedback (ETF) with loopgain $\mathscr{L}=\frac{\alpha P_{e}}{G_{0} T_{C}}$, where $\alpha$ is the logarithmic derivative of resistance with temperature, $\alpha=\frac{\partial \ln \left(R_{T E S}\right)}{\partial \ln (T)}, P_{e}$ is the electrical bias power, and $T_{c}$ is the superconducting transition temperature. The TES is read out with fMUX readout with an electrical time constant of $\tau_{e}=2 L / R_{T E S}$.

The bandwidth limit of the readout imposes a stability requirement on the thermal time constant of the detector $\left(\tau_{t h}\right)$ of:

$$
\tau_{t h}=\frac{C_{0}}{G_{0}} \frac{1}{\mathscr{L}+1}>5.8 \tau_{e} .
$$

Equation 1 is the extension of the one-body (simple TES) stability criteria to a twobody device in the limit that $\gamma \rightarrow \infty$ and $\eta \rightarrow \infty$. The original criteria is derived in Irwin et al. (1998) $\frac{5}{5}$ and Irwin and Hilton (2005) $\frac{6}{6}$ by requiring that the eigenvalues of the responsivity matrix be negative and real-valued. Equation 1 is the same as the stability criterion for a one-body TES, except $C_{T E S}$ is replaced by $C_{0}$ here. 


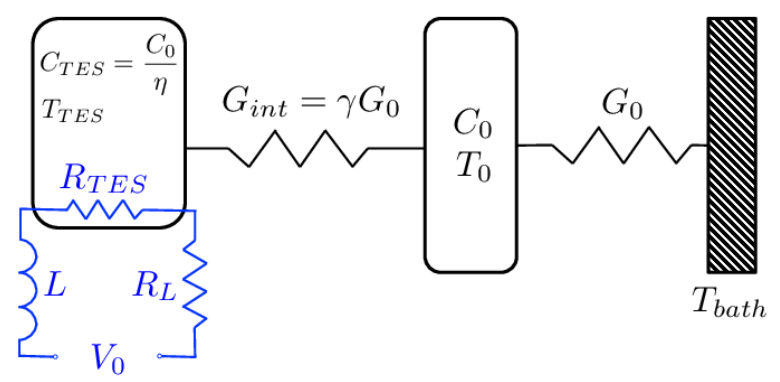

Fig. 1 (Color online) Black: Two-body thermal model used to model the thermal structure of our bolometers. The node in the middle represents the BLING with heat capacity $C_{0}$, coupled to the bath with a thermal link $G_{0}$. The left node is the TES, which is strongly coupled to the BLING with a thermal link $G_{i n t}=\gamma G_{0}$. Blue: Electrical circuit for the TES, with inductance $L$ and parasitic resistance $R_{L}$.

In a real compound device, the BLING is not perfectly coupled to the TES, and the TES has a finite heat capacity: $\gamma, \eta \gg 1$, but neither is infinite. The responsivity matrix is now more complicated (see Lueker $(2011)^{7}$ ) and the stability requirement that comes from requiring negative and real valued eigenvalues in the limit that $\tau_{t h} \gg \tau_{e}$ (i.e. the limit that equation 1 has already been satisfied) is:

$$
\mathscr{L}<\gamma+1+\frac{C_{T E S}}{G_{0} \frac{\gamma}{\gamma+1} \tau_{e}} .
$$

If $C_{T E S}$ is sufficiently large, then the device can remain stable without additional heat capacity. In our devices, $C_{T E S}$ is much too small and an additional heat capacity $C_{0}$ must be added to satisfy equation 1 . Because of this, the last term in equation 2 can be ignored, and equation 2 becomes a constraint on $\gamma$.

To meet these two stability criteria we need to engineer our bolometers to have a higher $\tau_{t h}$ and a higher $\gamma\left(\right.$ and $G_{i n t}$ ). We can increase the thermal time constant by adding heat capacity $\left(C_{0}\right)$ to the TES island $\stackrel{8}{\underline{8}}$, or by decreasing the loopgain $(\mathscr{L}) . G_{0}, T_{c}$, and $P_{e}$ are constrained by observational requirements, so we can only decrease $\mathscr{L}$ by decreasing $\alpha$, which can be accomplished with the addition of normal metal structures on the TES. ${ }^{10} \gamma$ can be increased by improving the interface between the TES and BLING.

\section{Device designs}

The base TES design is a $45 \mathrm{~nm}$ thick, $48 \mu \mathrm{m}$ wide Al-Mn TES with $\sim 1 \Omega$ normal resistance $\left(R_{n}\right)$ and a transition temperature of $\sim 540 \mathrm{mK}$. The TES has niobium leads overlapping the TES material on the two ends. Four nitride legs support the TES and provide the thermal link to the bath. The thermal conductance of the legs is $G_{0} \sim 120 \mathrm{pW} / \mathrm{K}$, to achieve a saturation power of $\sim 22 \mathrm{pW}$ at a bath temperature of $280 \mathrm{mK}$. To make devices with lower $\alpha$ (and $\mathscr{L}$ ), higher $C_{0}$, and higher $G_{\text {int }}$ (and $\gamma$ ), we considered four types of modifications to our basic design: 
1. Addition of gold BLING of various thicknesses to increase heat capacity $\left(C_{0}\right)$ and a range of geometries which probe the thermal coupling between the TES and BLING $(\gamma)$.

2. Addition of normal metal features (bars or dots) on the TES to soften the TES transition $(\alpha)$ and consequently decrease device loop gain $(\mathscr{L})$.

3. Substituting PdAu (52\% Pd by mass, DC sputter from an alloy target) for the Au BLING to decrease the thickness of BLING needed for a given heat capacity $\left(C_{0}\right)$.

4. Addition of a gold cap on top of an insulator above the TES to improve TESBLING coupling $(\gamma)$.

Combinations and variations of these four basic design modifications led to 40 different device designs. The resulting devices are listed in Table 1 All devices were fabricated on a single wafer with 10 devices per die $(1 \mathrm{~cm} \mathrm{x} 1 \mathrm{~cm})$ and 4 different types of dies corresponding to the devices in each column in Table 1, This ensured uniformity of the basic TES parameters such as normal resistance $\left(R_{n}\right)$ and thermal conductance $\left(G_{0}\right)$, allowing us to directly compare design changes. In the case of uniform $G_{0}, \gamma$ can be used directly as a proxy for $G_{\text {int }}$. Accounting for systematics in our test setup, these parameters were measured to be uniform at the $\sim 5 \%$ level.

\section{Measurements and Analysis}

To rapidly evaluate these 40 designs we used a simple technique described in Lueker et al. (2008) $\underline{\underline{8}}$ and Lueker (2011) $\underline{\underline{7}}$ to measure the internal thermal structure of these devices using frequency multiplexed readout. A TES is voltage biased with a carrier signal at a frequency $\omega_{0}$ and amplitude $V_{0}$. In addition to the carrier, we inject a small sinusoidal probe signal with amplitude $V^{\prime}$ at a frequency $\omega_{0}-\omega$ which will perturb the TES with a power $\delta P(\omega)=\left(V_{0} V^{\prime}\right) /\left(R_{T E S} \sqrt{1+\omega^{2} \tau_{e}^{2}}\right)$. The amplitude of the current measured in the opposite sideband, $\left|I_{s b}\left(\omega_{0}+\omega\right)\right|$, is proportional to the power-to-current responsivity $s_{i}(\omega)$. Ignoring parameters that are expected to be negligible under our operating conditions $\left(\beta=\frac{\partial \ln \left(R_{T E S}\right)}{\partial \ln (I)} \ll 1\right.$, $\left.R_{L} \ll 1\right)$, the equation is $\left|I_{s b}\left(\omega_{0}+\omega\right)\right|=\frac{V^{\prime} V_{0}}{R_{T E S}} \mid \frac{\left|s_{i}(\omega)\right|}{1+i \omega \tau_{e}}$, , which expands to:

$$
\left|I_{s b}\left(\omega_{0}+\omega\right)\right|=\frac{V^{\prime} \mathscr{L}}{R_{T E S} \sqrt{1+\omega^{2} \tau_{e}^{2}}}\left|\left(\frac{G(\omega)}{G_{e f f}}\left(1+i \omega \tau_{e}\right)+\mathscr{L}\left(1-i \omega \tau_{e}\right)\right)^{-1}\right|
$$

where $G(\omega)$ is the generalized thermal conductance defined in Lanting et al. (2005) 11 and $G_{e f f}$ is the effective thermal conductance at the TES, which for the two-body model is $G_{e f f}=G_{0} \frac{\gamma}{\gamma+1}$.

The form of $G(\omega)$ depends on the bolometer thermal model chosen, and for the two-body model is

$$
G(\omega)=G_{0} \frac{\gamma}{1+\gamma}\left(\frac{1+i \omega \frac{C_{0}}{G_{0}}}{1+i \omega \frac{C_{0}}{(1+\gamma) G_{0}}}\right) .
$$


Equation 4 can be combined with equation 3 to obtain a model for $\left|I_{s b}\left(\omega_{0}+\omega\right)\right|$ which contains only relevant device parameters $\left(R_{T E S}, \tau_{0}=C_{0} / G_{0}, \gamma=G_{\text {int }} / G_{0}\right.$, and $\mathscr{L}$ ) and parameters of the system $\left(\tau_{e}\right.$ and $\left.V^{\prime}\right) . \tau_{0}$ is the intrinsic thermal time constant of the detector as $\eta, \gamma \rightarrow \infty$ and $\mathscr{L} \rightarrow 0$.

We bias each TES to a depth in the superconducting transition, $f_{R}=R_{T E S} / R_{n}$, and measure $\left|I_{s b}\left(\omega_{0}+\omega\right)\right|$ at probe offset frequencies $(\omega / 2 \pi)$ from $3-40,000 \mathrm{~Hz}$, and repeat this measurement for $f_{R}$ from 0.6-0.99. We extract $\tau_{0}$ by fitting the data trace taken at $f_{R}=0.99$ to equations 3 and 4 using a fixed, low loop gain $(\mathscr{L} \sim 0)$. We then simultaneously fit all remaining data traces to equations 3 and 4 fixing $\tau_{0}$ to the value extracted from the fit at $f_{R}=0.99$. To simplify modeling $\gamma$ is constrained to be the same at each $f_{R}$. $\tau_{e}$ is fixed individually in each trace to be $2 L /\left(f_{R} R_{n}\right)$. We allow $\mathscr{L}$ to vary in each trace, denoted as $\mathscr{L}\left(f_{R}\right)$.

Of the 40 types of devices fabricated, 39 were measured and the resulting data fit to the two-body bolometer model using the procedure described in this section. Figure 2 shows the data and model fits obtained for two TESes.

\section{Discussion}

The two-body model described by equations 3 and 4 adequately models the detector response over the range of the superconducting transition where we normally operate our detectors $\left(f_{R}=0.6-0.99\right)$, and we can extract the parameters $\tau_{0}, \gamma$, and $\mathscr{L}\left(f_{R}\right)$ from the fits to this model. Table 1 lists the parameters extracted from the fits for each TES. The model parameters reported in Table 1 can be used to evaluate the effectiveness of various design modifications described in Section 3 . Comparing devices across a row or down a column in Table 1 is a direct comparison of individual design changes.

Each row has a fixed TES-BLING interface, which allows comparison between the effects of adding different structures to the TES. For example, comparing across row 1 reveals that the addition of bars between type 1,1 and type 2,1 decreased $\mathscr{L}(0.6)$ by reducing the $\alpha$ of the superconducting transition, while not affecting the intrinsic time constant $\left(\tau_{0}\right)$ or the TES-BLING coupling $(\gamma)$. Comparing type 2,1 with type 4,1 reveals that the addition of a gold/insulator cap over the TES both decreases $\mathscr{L}(0.6)$ and increases $\gamma$ while leaving $\tau_{0}$ almost unchanged. Comparing devices down a column reveals the effect of changes to the TES-BLING interface geometry. For example, if we compare type 1,1 and type 1,5 in column 1, we find that simply extending the BLING past the Nb leads into the TES region increases the TES-BLING coupling $(\gamma)$ by a factor of $\sim 2$.

Evaluating the data on the group of devices as a whole, several trends can be seen. These are:

1. The geometry of the TES-BLING interface is important for TES-BLING coupling. In particular, direct metal contact between the BLING and TES drastically increases $\gamma$, when compared to contact through an intermediate dielectric or superconducting barrier with similar physical dimensions.

2. The addition of bars or other structures on the TES lowers $\alpha$ (and $\mathscr{L}$ ).

3. The addition of a gold/insulator cap over the TES lowers $\alpha$ (and $\mathscr{L}$ ), and increases $\gamma$. 

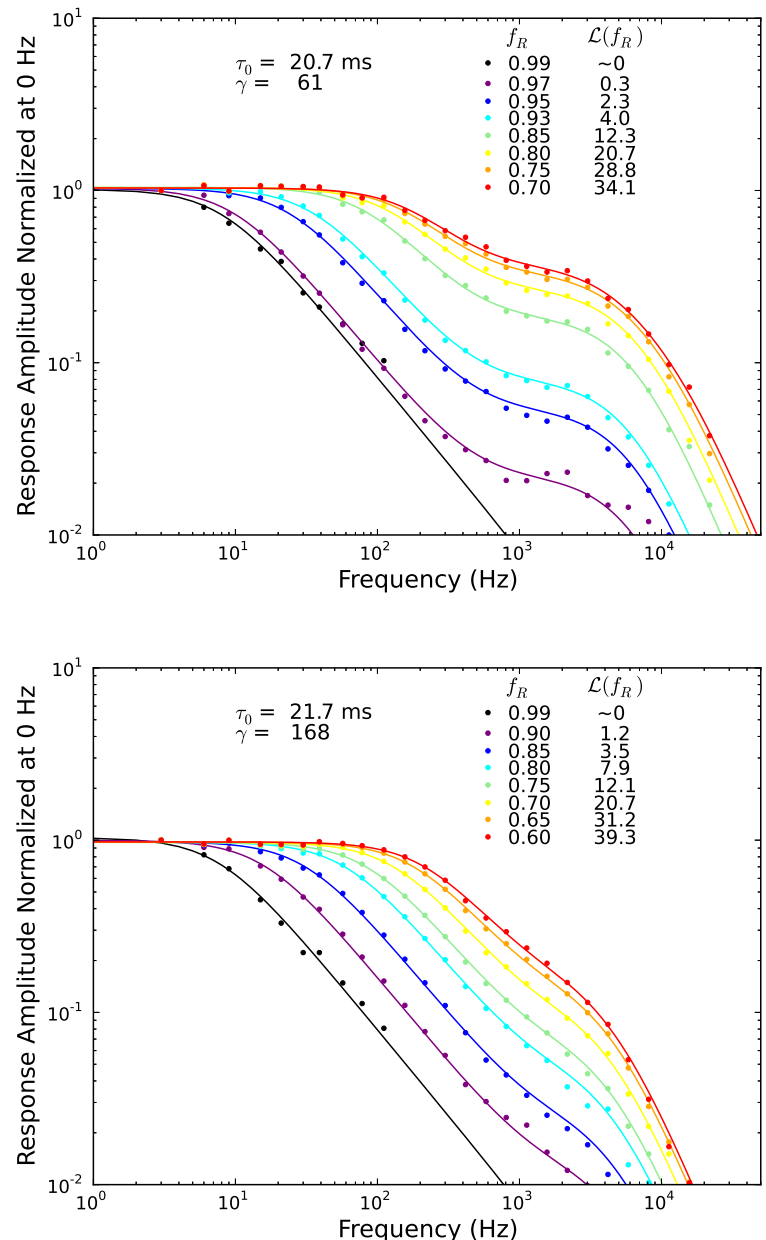

Fig. 2 (Color online) Normalized frequency response of two detectors with similar intrinsic time constants $\left(\tau_{0}\right)$ but vastly different internal coupling of the bling to the TES $(\gamma)$. The dots are the measured data points and the lines are a fit to equations 3 and 4 Traces from left to right on the plot go from higher to lower $f_{R}=R_{T E S} / R_{n} . \mathscr{L}\left(f_{R}\right)$ is the loop gain at $f_{R}$. The models were fit using the method described in Section 4 In the device with lower $\gamma$ (top), the BLING decoupling is obvious at a frequency of $\sim 800 \mathrm{~Hz}$. Top: One detector of type 1,2. Bottom: One detector of type 1,5 .

\section{Conclusions}

Using the two-body bolometer model to describe the thermal response of our TES samples, we extract model parameters that affect TES stability: $\tau_{0}, \mathscr{L}\left(f_{R}\right)$ (and $\alpha$ ), and $\gamma\left(\right.$ and $G_{i n t}$ ), for each of our various TES designs. By comparing the model parameters for each design, we can evaluate which TES design changes to employ to optimize our device operation. We find that various interfaces between 
the BLING and TES improve the BLING-TES coupling by factors of 2-3 with a $G_{\text {int }}$ ranging from $\sim 7-20 \mathrm{nW} / \mathrm{K}$ over the various designs. We also find that various structures on the TES can degrade $\alpha$, and hence $\mathscr{L}$, by factors of $2-8$ at $0.6 R_{n}$, the deepest point in the transition that we typically operate our detectors.

Our study of these 40 different TES samples resulted in 40 TES designs that could be operated stably at moderate loopgains, and showed none of the excess noise from poorly coupled BLING that early prototypes displayed (see section 5.2 of Lueker $(2011)^{\frac{7}{}}$ ). The results of this study were incorporated into the design of stable TES detectors deployed in the SPTpol array. ${ }^{2}$ The fielded devices have $540 \mathrm{~nm}$ thick PdAu BLING, with a TES-BLING interface such that the BLING extends past $\mathrm{Nb}$ leads into TES region, and no bars or structures on the surface of the TES.

Acknowledgements Work at the University of Colorado is supported by the NSF through grant AST-0705302. Work at NIST is supported by the NIST Innovations in Measurement Science program. The McGill authors acknowledge funding from the Natural Sciences and Engineering Research Council, Canadian Institute for Advanced Research, and Canada Research Chairs program. MD acknowledges support from an Alfred P. Sloan Research Fellowship. Work at the University of Chicago is supported by grants from the NSF (awards ANT-0638937 and PHY0114422), the Kavli Foundation, and the Gordon and Betty Moore Foundation. Work at Argonne National Lab is supported by UChicago Argonne, LLC, Operator of Argonne National Laboratory (Argonne). Argonne, a U.S. Department of Energy Office of Science Laboratory, is operated under Contract No. DE-AC02-06CH11357. We acknowledge support from the Argonne Center for Nanoscale Materials.

\section{References}

1. J. Henning, et al. Society of Photo-Optical Instrumentation Engineers Conference Series. 8452 (2012).

2. E. M. George, et al. Society of Photo-Optical Instrumentation Engineers Conference Series. 8452 (2012).

3. M. Dobbs, E. Bissonnette, and H. Spieler. IEEE Transactions on Nuclear Science. 552126 (2008).

4. J. Hubmayr, et al. IEEE Transactions on Applied Superconductivity. 21, 3, 203-206 (2011).

5. K. D. Irwin, G. C. Hilton, D. A. Wollman, and J. M. Martinis. Journal of Applied Physics 838 (1998).

6. K. D. Irwin and G. C. Hilton. Cryogenic Particle Detection 63 (2005).

7. M. Lueker. Berkeley University Press. PhD Thesis (2011).

8. M. Lueker, B. A. Benson, C. L. Chang, H. M. Cho, M.Dobbs, W. L. Holzapfel, T. Lanting, A.T. Lee, J. Mehl, T. Plagge, E. Shirokoff, H. G. Spieler, and J. D. Vieira. IEEE Transactions on Applied Superconductivity. 19496500 (2009).

9. E. Shirokoff et al. IEEE Transactions on Applied Superconductivity. 19 517519 (2009).

10. J.G.Staguhn et al. Nuclear Instrumentation and Methods in Phys Res A. 520 336339 (2004).

11. T. M. Lanting et al. Applied Physics Letters. 86 112511-112513 (2005). 


\begin{tabular}{|c|c|c|c|c|c|c|c|c|c|c|c|c|}
\hline Var. & & Type 1 & $\begin{array}{l}\tau_{0} \\
\gamma \\
\mathscr{L}^{*}\end{array}$ & & Type 2 & $\begin{array}{l}\tau_{0} \\
\gamma \\
\mathscr{L}^{*} \\
\end{array}$ & & Type 3 & $\begin{array}{l}\tau_{0} \\
\gamma \\
\mathscr{L}^{*} \\
\end{array}$ & & Type 4 & $\begin{array}{l}\tau_{0} \\
\gamma \\
\mathscr{L}^{*}\end{array}$ \\
\hline 1 & & $\begin{array}{l}\text { Symmetric Au bling } \\
3350 \mathrm{~nm} \text {. Usual inter- } \\
\text { face. }\end{array}$ & $\begin{array}{l}24 \\
84 \\
51\end{array}$ & $\square$ & $\begin{array}{l}\text { Symmetric Au bling } 3350 \\
\text { nm. Usual interface. } 3 \text { Au } \\
\text { bars each } 2 \mu \mathrm{m} \mathrm{x} 43 \mu \mathrm{m} \mathrm{x} \\
350 \mathrm{~nm} \text {. }\end{array}$ & $\begin{array}{l}24 \\
83 \\
33\end{array}$ & & $\begin{array}{l}\text { Symmetric PdAu bling } \\
375 \mathrm{~nm} \text {. Usual interface. } 3 \\
\text { PdAu bars each } 2 \mu \mathrm{m} \times 43 \\
\mu \mathrm{m} \times 375 \mathrm{~nm} .\end{array}$ & $\begin{array}{l}11 \\
84 \\
12\end{array}$ & . & $\begin{array}{l}\text { Symmetric Au bling } 3350 \mathrm{~nm} \text {. } \\
\text { Usual interfaces. } 3 \text { Au bars } 2 \mu \mathrm{m} \\
\text { x } 43 \mu \mathrm{m} \text { x } 350 \mathrm{~nm}+4 \mu \mathrm{m} \times 44 \\
\mu \mathrm{m} \times 3000 \mathrm{~nm} \text {. Au cap } 3000 \mathrm{~nm} \text {. }\end{array}$ & $\begin{array}{l}22 \\
131 \\
8\end{array}$ \\
\hline 2 & & $\begin{array}{l}\text { Monolithic } \mathrm{Au} \text { bling } \\
3350 \mathrm{~nm} \text {. }\end{array}$ & $\begin{array}{l}17 \\
52 \\
30\end{array}$ & & $\begin{array}{l}\text { Monolithic Au bling } 3350 \\
\mathrm{~nm} .3 \mathrm{Au} \text { bars each } 2 \mu \mathrm{m} \text { x } \\
43 \mu \mathrm{m} \text { x } 350 \mathrm{~nm} \text {. }\end{array}$ & $\begin{array}{l}19 \\
60 \\
22\end{array}$ & & $\begin{array}{l}\text { Monolithic PdAu bling } 375 \\
\text { nm. } 3 \text { PdAu bars each } 2 \mu \mathrm{m} \\
\text { x } 43 \mu \mathrm{m} \text { x } 375 \mathrm{~nm} \text {. }\end{array}$ & $\begin{array}{l}13 \\
70 \\
18\end{array}$ & & $\begin{array}{l}\text { Monolithic Au bling } 3350 \mathrm{~nm} .3 \\
\text { bars } 2 \mu \mathrm{m} \text { x } 43 \mu \mathrm{m} \times 350 \mathrm{~nm}+4 \\
\mu \mathrm{m} \times 44 \mu \mathrm{m} \times 3000 \mathrm{~nm} \text {. Au cap } \\
3000 \mathrm{~nm} .\end{array}$ & $\begin{array}{l}25 \\
138 \\
12\end{array}$ \\
\hline 3 & & $\begin{array}{l}\text { Symmetric } \quad \text { Au bling } \\
3350 \text { nm. Extra wide } \\
\text { LSN gap. }\end{array}$ & $\begin{array}{l}24 \\
99 \\
44\end{array}$ & & $\begin{array}{l}\text { Symmetric PdAu bling } \\
375 \mathrm{~nm} \text {. Extra wide LSN } \\
\text { gap. } 3 \text { bars each } 2 \mu \mathrm{m} \times 43 \\
\mu \mathrm{m} \times 350 \mathrm{~nm} .\end{array}$ & $\begin{array}{l}21 \\
73 \\
29\end{array}$ & & $\begin{array}{l}\text { Symmetric PdAu bling } \\
\text { 375nm. Extra wide LSN } \\
\text { gap. } 3 \text { PdAu bars each } 2 \mu \mathrm{m} \\
\text { x } 43 \mu \mathrm{m} \text { x } 375 \mathrm{~nm} \text {. }\end{array}$ & $\begin{array}{l}16 \\
105 \\
6\end{array}$ & & $\begin{array}{l}\text { Symmetric Au bling } 350 \mathrm{~nm} \text {. Ex- } \\
\text { tra wide LSN gap. } 3 \text { thin bars } 2 \\
\mu \mathrm{m} \times 43 \mu \mathrm{m} \times 350 \mathrm{~nm} .\end{array}$ & $\begin{array}{l}9 \\
84 \\
19\end{array}$ \\
\hline 4 & & $\begin{array}{l}\text { Monolithic AlMn bling } \\
45 \mathrm{~nm} \text {. }\end{array}$ & $\begin{array}{l}7 \\
53 \\
27\end{array}$ & & $\begin{array}{l}\text { Monolithic Au bling } 350 \\
\mathrm{~nm} \text {. }\end{array}$ & $\begin{array}{l}8 \\
67 \\
51\end{array}$ & & $\begin{array}{l}\text { Monolithic PdAu bling } 375 \\
\text { nm. }\end{array}$ & $\begin{array}{l}12 \\
62 \\
25\end{array}$ & & $\begin{array}{l}\text { Monolithic Au bling } 3350 \mathrm{~nm} \text {. } \\
\text { Au cap } 3000 \mathrm{~nm} \text {. }\end{array}$ & $\begin{array}{l}22 \\
114 \\
11\end{array}$ \\
\hline 5 & & $\begin{array}{l}\text { Symmetric } \mathrm{Au} \text { bling } \\
3350 \mathrm{~nm} \text {, extends past } \\
\mathrm{Nb} \text { leads into TES } \\
\text { region. }\end{array}$ & $\begin{array}{l}21 \\
152 \\
46\end{array}$ & & $\begin{array}{l}\text { Symmetric Au bling } 3350 \\
\mathrm{~nm} \text {, extends past } \mathrm{Nb} \text { leads } \\
\text { into TES region. } 3 \text { bars, each } \\
2 \mu \mathrm{m} \times 43 \mu \mathrm{m} \times 350 \mathrm{~nm} .\end{array}$ & $\begin{array}{l}23 \\
181 \\
44\end{array}$ & & $\begin{array}{l}\text { Symmetric PdAu bling } 375 \\
\text { nm, extends past Nb leads } \\
\text { into TES region. } 3 \text { PdAu } \\
\text { bars each } 2 \mu \mathrm{m} \times 43 \mu \mathrm{m} x \\
375 \mathrm{~nm} \text {. }\end{array}$ & $\begin{array}{l}11 \\
133 \\
6\end{array}$ & & $\begin{array}{l}\text { Symmetric Au bling } 3350 \mathrm{~nm} \text {, } \\
\text { extends past Nb leads into TES } \\
\text { region. } 3 \text { bars } 2 \mu \mathrm{m} \times 43 \mu \mathrm{m} \times \\
350 \mathrm{~nm}+4 \mu \mathrm{m} \mathrm{x} 44 \mu \mathrm{m} \times 3000 \\
\mathrm{~nm} \text {. Au cap } 3000 \mathrm{~nm} \text {. }\end{array}$ & $\begin{array}{l}25 \\
148 \\
16\end{array}$ \\
\hline 6 & & $\begin{array}{lll}\text { Symmetric } & \text { Au } & \text { bling } \\
3350 \mathrm{~nm}, & \text { no } & \text { AlMn } \\
\text { under bling. } & & \end{array}$ & $\begin{array}{l}22 \\
81 \\
48\end{array}$ & & $\begin{array}{l}\text { Symmetric Au bling } 3350 \\
\text { nm, no AlMn under bling. } 3 \\
\text { Au bars each } 2 \mu \mathrm{m} \text { x } 43 \mu \mathrm{m} \\
\text { x } 350 \mathrm{~nm} \text {. }\end{array}$ & $\begin{array}{l}24 \\
70 \\
19\end{array}$ & & $\begin{array}{l}\text { Symmetric PdAu bling } 375 \\
\text { nm, no AlMn under bling. } 3 \\
\text { PdAu bars each } 2 \mu \mathrm{m} \times 43 \\
\mu \mathrm{m} \times 375 \mathrm{~nm} .\end{array}$ & $\begin{array}{l}15 \\
102 \\
20\end{array}$ & & $\begin{array}{l}\text { Symmetric Au bling } 3350 \mathrm{~nm} \text {, } \\
\text { no AlMn under bling. } 3 \text { Au bars } \\
2 \mu \mathrm{m} \times 43 \mu \mathrm{m} \times 350 \mathrm{~nm}+4 \mu \mathrm{m} \\
\mathrm{x} 44 \mu \mathrm{m} \times 3000 \mathrm{~nm} .\end{array}$ & $\begin{array}{l}20 \\
58 \\
14\end{array}$ \\
\hline 7 & & $\begin{array}{ll}\text { Symmetric } & \text { Au bling } \\
3350 \mathrm{~nm} . & \text { (Same as } \\
\text { Type1-1) } & \end{array}$ & $\begin{array}{l}17 \\
56 \\
20\end{array}$ & & $\begin{array}{l}\text { Symmetric Au bling } 3350 \\
\mathrm{~nm} \text {. Au dots each } 2 \mu \mathrm{m} \times 2 \\
\mu \mathrm{m} \times 350 \mathrm{~nm}, 6 \text { columns by } \\
11 \text { rows. }\end{array}$ & $\begin{array}{l}19 \\
65 \\
27\end{array}$ & & $\begin{array}{l}\text { Symmetric PdAu bling } 375 \\
\text { nm. PdAu dots each } 2 \mu \mathrm{m} \times \\
2 \mu \mathrm{m} \times 375 \mathrm{~nm}, 6 \text { columns } \\
\text { by } 11 \text { rows. }\end{array}$ & $\begin{array}{l}14 \\
101 \\
21\end{array}$ & & $\begin{array}{l}\text { Au bling intermediate size } 3350 \\
\mathrm{~nm}+\mathrm{rest} 350 \mathrm{~nm} \text {. Au dots each } 2 \\
\mu \mathrm{m} \times 2 \mu \mathrm{m} \times 350 \mathrm{~nm}, 6 \text { columns } \\
\text { by } 11 \text { rows. }\end{array}$ & $\begin{array}{l}18 \\
85 \\
17\end{array}$ \\
\hline 8 & & $\begin{array}{l}1 \text { piece Au bling } 3350 \\
\text { nm. Gap around TES. } \\
\text { No TES/bling metal } \\
\text { contact. }\end{array}$ & $\begin{array}{l}19 \\
50 \\
51\end{array}$ & & $\begin{array}{l}\text { 1 piece Au bling } 3350 \\
\mathrm{~nm} \text {. Gap around TES. No } \\
\text { TES/bling metal contact. } 1 \\
\text { Au bar } 5 \mu \mathrm{m} \times 43 \mu \mathrm{m} \times 350 \\
\mathrm{~nm} \text {. }\end{array}$ & $\begin{array}{l}19 \\
47 \\
24\end{array}$ & & $\begin{array}{l}\text { 1 piece PdAu bling } 375 \mathrm{~nm} \text {. } \\
\text { Gap around TES. No } \\
\text { TES/bling metal contact. } 1 \\
\text { PdAu bar } 5 \mu \mathrm{m} \times 43 \mu \mathrm{m} \mathrm{x} \\
375 \mathrm{~nm} \text {. }\end{array}$ & $\begin{array}{l}13 \\
55 \\
30\end{array}$ & & $\begin{array}{l}1 \text { piece Au bling } 3350 \mathrm{~nm} \text {. } \\
\text { Gap around TES. No TES/bling } \\
\text { metal contact. } 1 \text { Au bar } 5 \mu \mathrm{m} \times \\
43 \mu \mathrm{m} \times 3350 \mathrm{~nm} \text {. Au cap } 3000 \\
\mathrm{~nm} \text {. }\end{array}$ & $\begin{array}{l}22 \\
115 \\
12\end{array}$ \\
\hline 9 & 东 & $\begin{array}{l}\text { Symmetric } \mathrm{Au} \text { bling } \\
3350 \mathrm{~nm} .1 \mathrm{Au} \text { bar } 2 \\
\mu \mathrm{m} \times 43 \mu \mathrm{m} \times 3350 \mathrm{~nm} .\end{array}$ & $\begin{array}{l}23 \\
81 \\
30\end{array}$ & $\square$ & $\begin{array}{l}\text { Symmetric Au bling } 3350 \\
\mathrm{~nm} \text {. } 1 \mathrm{Au} \text { bar } 5 \mu \mathrm{m} \times 43 \\
\mu \mathrm{m} \times 3350 \mathrm{~nm} \text {. Gap around } \\
\text { TES. No TES/bling metal } \\
\text { contact. }\end{array}$ & $\begin{array}{l}21 \\
65 \\
27\end{array}$ & & $\begin{array}{l}\text { Symmetric PdAu bling } 375 \\
\mathrm{~nm} .1 \text { PdAu bar } 5 \mu \mathrm{m} \text { x } 43 \\
\mu \mathrm{m} \times 375 \mathrm{~nm} \text {. Gap around } \\
\text { TES. No TES/bling metal } \\
\text { contact. }\end{array}$ & $\begin{array}{l}13 \\
92 \\
20\end{array}$ & 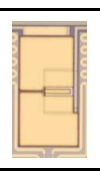 & $\begin{array}{l}\text { Symmetric Au bling } 3350 \mathrm{~nm} .1 \\
\text { Au bar } 5 \mu \mathrm{m} \text { x } 43 \mu \mathrm{m}+350 \mathrm{~nm} \\
+7 \mu \mathrm{m} \times 44 \mu \mathrm{m} \text { x } 3350 \mathrm{~nm} . \mathrm{Au} \\
\text { cap } 3000 \mathrm{~nm} .\end{array}$ & $\begin{array}{l}24 \\
82 \\
7\end{array}$ \\
\hline 10 & 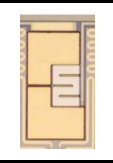 & $\begin{array}{l}\text { Symmetric } \mathrm{Au} \text { bling } \\
3350 \mathrm{~nm} .3 \mathrm{Au} \text { bars } 2 \\
\mu \mathrm{m} \times 36 \mu \mathrm{m} \times 350 \mathrm{~nm} .\end{array}$ & NA & 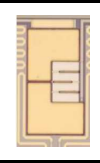 & $\begin{array}{l}\text { Symmetric Au bling } 3350 \\
\text { nm. } 3 \text { Au bars } 2 \mu \mathrm{m} \times 48 \mu \mathrm{m} \\
\text { x } 350 \mathrm{~nm}+75 \% \text { fractional } \\
\text { width } 2 \mu \mathrm{m} \times 36 \mu \mathrm{m} \times 350 \\
\mathrm{~nm} .\end{array}$ & $\begin{array}{l}20 \\
64 \\
17\end{array}$ & & $\begin{array}{l}\text { Symmetric PdAu bling } 375 \\
\mathrm{~nm} .3 \text { PdAu bars } 2 \mu \mathrm{m} \text { x } 48 \\
\mu \mathrm{m} \times 350 \mathrm{~nm} .\end{array}$ & $\begin{array}{l}12 \\
87 \\
16\end{array}$ & 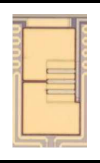 & $\begin{array}{l}\text { Symmetric Au bling } 3350 \mathrm{~nm} .3 \\
\text { Au bars } 2 \mu \mathrm{m} \text { x } 48 \mu \mathrm{m} \text { x } 350 \mathrm{~nm} \text {. } \\
\text { Au cap } 3000 \mathrm{~nm} .\end{array}$ & $\begin{array}{l}26 \\
142 \\
21\end{array}$ \\
\hline
\end{tabular}

Table 1 (Color online.) TES Parameters from fit to two-body thermal detector model. The intrinsic thermal time constant, $\tau_{0}$, is reported in milliseconds. $\gamma$ is the ratio of the internal to external thermal conductances $\left(G_{\text {int }} / G_{0}\right)$. $\mathscr{L}^{*}$ is the loop gain; due to space considerations, only $\mathscr{L}(0.6)$ is reported. In cases where measurements were made on more than one device of a particular type, the fit parameters were averaged. Unless otherwise stated, the BLING is deposited on top of a layer of Al-Mn put down during the TES deposition. "Usual interfaces" denotes the BLING extending over the TES leads. Each row has a fixed TES-BLING interface, which allows comparison between the effects of adding different structures to the TES. 